\title{
Direct Speech Act in Communication between Saudi Arabian Family Members
}

\author{
Sawsan Abdulmohsen Alfaleh \\ King Saud University \\ Saudi Arabia
}

\begin{abstract}
This research article aims to explore the direct speech act as used in Arabic language and in particular in the Saudi Arabian family context where Najdi dialect is used. The article analyses spoken conversations as data gained, and then transcribed, from Saudi family interactions in a series uploaded on YouTube. The analysis focuses on three areas: direct request speech act, the cultural impact of used forms and strategies, and the notion of face threatening in everyday Saudi family interactions. The study sheds light on one exemplary speech act, 'request'. The analysis focuses on three areas: direct request speech act, the cultural influence and the notion of face threatening. Results show tendency of Saudi family members to the use some Islamic forms in request (making and responsel decline or acceptance). Results also show that the use of religious forms such as Masha Allah and Insha'Allah could increase the pragmatic rejection of request by interactant(s) or have some mitigating role. Article is structures as follows: an introduction followed by theoretical literature related to the topic of study, and then a methodology precedes the analysis, findings and discussion. The article ends with a conclusion.
\end{abstract}

Keywords: pragmatics, speech act, faces threat, request, directness.

\section{Introduction}

Pragmatics is considered an essential part of language studies, especially when considering the relationship between language and contextual use. It is therefore important for creating and maintaining relationships. Inability to understand the norms (and the pragmatics of a language) can lead a language user to a pragmatic failure. Language is seen by (Searle, 1975) as a form of behavior that is governed by strict set of rules, and this speech act theory is based on the assumption that the speech act/utterance is the minimal unit of linguistic communication. And it serves a particular function in communication. Such acts include, for example, giving reports, making promises, apologizing, inviting, requesting, praising, criticizing, complaining, and so forth. According to Austin, communication is looked at as a series of communicative acts or speech acts that constitute the framework of communication.

Factors like sex, age, culture, etc. also play a critical part in people's interaction, especially in a face to face personal contact. Certain rules can be used by a speaker in order to communicate with other people effectively and to avoid misunderstanding and, thus, any pragmatic failure. Speech acts include functional communication, for example, excuses, compliments and commitments (Austin, 1975) that are used in all languages and cultures. However, the forms of an act may vary according to the culture and language, and thus imply different interpretations.

In addition to the use of these speech acts, there exists the universal principle of politeness (Brown \& Levinson, 1987). Such strategies as politeness, for example, can be observed in (and along with) different speech acts. The choice of forms made by the interactants can be considered polite or rude depending on the situation, relationship type (e.g. affinity), culture, society and/or audience. It is directness in an utterance what may raise the point of (im)politeness.

This article investigates the determinants of directness in Saudi family interaction, explores the impact of culture on request strategy choice, and verifies whether or not familial interactions have the issue of face threat when direct requests are made. In this article, the following questions will be sought to be answered:

1. What are the main determinants of directness for Saudi family members when approaching requests?

2. How does culture influence the choice of strategies, namely in regards to request and response to requests?

3. Does the everyday interaction between Saudi family members raise any perceived face threat issue due to 'directness'?

\section{Literature Review}

Focusing on the related studies would help understand the relationship between such variables as 'culture and gender' and notions in pragmatics such as face threatening, politeness, indirectness, etc. It, therefore, briefly introduces the main notions and theories upon which the current article is based. 
Austin (1975) stressed that the speech is a balance between an expression and an official speech (performative utterances). (Huang, 2006:93) stated that "the basic principle of [every day] discourse is the action of a sentence or part of an action within a social system and the framework of a convention". Speech is an act. For Searle (1975:50), the speech act occurs "when the speaker utters a sentence"; and acts could be seen in examples thereof like complaints, requests and invitations (Al-Kahtani, 2005). That said, meaning of what is said is not always literal. This means that the meaning is more than what is actually spoken. It usually functions illiterally, i.e. intentionally. Therefore, to complain or request, for example, one can make that directly or indirectly (Blum-Kulka, 1984).

The notion of (in) directness might be perceived in different cultures differently, and an utterance or a sentence may be perceived as a face threatening act (FTA) (Huang, 2006). Furthermore, in terms of social restrictions, there might be systematic differences in the models required for speech acts (Blum-Kulka, 1984). In Saudi families, for example, gender relations play an important role in the exchange of communication between family members. This raises the issue of influence of society, culture and social variable such as gender on the use and perception of speech acts. Brown and Levinson (1987) mentioned that FTAs might have consequences on both speakers and listeners. As face is considered a main notion in a conversation setting, failure to observe the notion of face can lead into humiliating or losing one's face (Brown \& Levinson, 1987).

Making the request, for example, should be achieved politely, and the answer to a request (whether by declining or accepting it) should also be made politely. The choice of an answer can be shameful, degrading, or losing face (Brown \& Levinson, 1987). Therefore, in an intervention request, the speaker threatens the public, but a minimized request can return FTA and may lose face (Blum-Kulka, 1984). Brown and Levinson's theory of politeness (1987) focuses on courtesy in three irrelevant languages; however, it has been noticed that these languages do not apply what might be looked at in Arabic as polite and non-face threatening when making direct requests (Bowe, 2014). For example, the commands are interpreted as rude in English, but courteous in other languages, such as Arabic (Al-Marrani \& Sazalie, 2010).

Nevertheless, Blum-Kulka, House and Casper (1989) explained that the head act of certain requests across different languages have different levels of directness which include a direct strategy, a traditional strategy and non-traditional indirect strategy. According to the analysis of Blum-Kulka (1984), speakers should include head act of a request, support actions, and internal changes with certain moves and internal modifications. These strategies can occur before or after the behavior of the head act of request (Blum-Kulka et al., 1989). Based on that, direct requests can lead to an FTA, but there are certain levels of directness as well as courtesy to reduce face threat.

The directness of the discourse is courtesy, because it refers to clarity, to the orientation of purpose and form. According to Economidou-Kogetsidis (2005), the directness of British and Greek English can be implicit in a different culture. What can be expressed directly in one culture might, in another culture, be expressed with less directness or even perceived as indirect (Blum-Kulka \& Olshtain, 1984). People with the same language and culture can also have different presentations according to gender, age or level of education influence (Blum-Kulka \& Olshtain, 1984). Social power and distance can influence the directness (of consultation strategies, for example) in Saudi Arabia and the United States (Tawalbehand \& Al-Oqaily, 2012).

Studies have shown that there are differences in the construction requirements of interlocutors in the United States and Saudi Arabia (Tawalbeh \& Al-Oqaily, 2012). Americans generally use indirect consultations, and if the consultation is not heavy, they can use direct consultations with friends and family (Tawalbeh \& Al-Oqaily, 2012). Furthermore, according to Al-Marrani and Sazalie (2010), Arab Yemeni users prefer to use direct strategies as instructed consultation strategies with people of equal status and listeners. According to Tawalbeh and Al-Oqaily (2012), openness (and directness) in Saudi culture expresses intimacy and affiliation. However, in other cultures, this directness can be considered rudeness. Therefore, cultural differences play a role in creating communication barriers and pragmatic failures (Horezeanu, 2015).

Pragmatics of language can vary from one culture to another. Other factors such as the received education or learning may also affect the level of pragmatic competence. According to Wallentin and Frith (2008), there may be a correlation between the structure of language and the way people learn a language. This means that people are born and grow in such a way that qualify them to be pragmatic and interact (in)correctly in culture specific interactions. Culture is one of the most important factors influencing the rules of interaction and communication (Ogiermann, 2008). Therefore, what is practiced in mother tongue may differ from other languages and cultures wherein an utterance may be considered coarse (Tawalbeh \& Al Oqaily, 2012). It should be mentioned in this place, as well, that a certain use of language may come and transfer from a generation of language users to another (Wallentin \& Frith, 2008), showing a relationship between the language structure and the way people learn the pragmatics of language. 
Needless to stress that Saudi culture and social variables as sex, age and relationships can impact the way of communication in Saudi Arabia (Commins, 2015). Saudi Arabia is a "typical" Muslim country, influenced by Islamic culture in different areas, including communication (Commins, 2015). The family structure of Saudi Arabia depends on gender and culture. The role of the father in the family is to protect the family, while the mother is responsible for the family. The role of the mother is to take care of children ("Cultural Portfolio", 2006), a thing that may also influence forms of communication.

Among the Saudis, righteousness is related to directness; and it is, therefore, the most popular strategy (Tawalbeh and Al-Oqaily, 2012). The importance of this stems from realizing that directness refers "to the extent to which the extraordinary intentions of the speaker are evident from language" (Bloom-Kulka, 1987:278). In other words, using a direct query is an explicit way of telling what should be done, and the individual as well as the public can understand the direct request (Krulatz, 2012).

In Saudi Arabia, directness is not considered impolite; nevertheless, the refusal of directness in requests, for example, can be something difficult to do. People of Arabic language often use the phrase 'Insha'Allah' (meaning at 'God willing') and the phrase 'Masha Allah' (to indicate to what 'God willed'. Saudi speakers use these two forms in their conversation generally. These religious terms can be used for future and past actions (Maalej, 2018). However, these phrases can be misinterpreted by the speakers belonging to both Saudi Arabia and English speakers (Horezeanu, 2015). The term 'Insha'Allah' can be interpreted as an indirect form used by the speaker(s) to decline/refuse a direct request i.e. can be used as a mitigating device for declining a request (Nazzal, 2005, cited in Maalej, 2018).

These terms, however, can be misinterpreted due to the tone and context of the word, even in times when the speaker has no intention to decline the request. People who are not experts can face a problem in a situation of unintended decline. Therefore, "Insha'Allah" and "MashaAllah" have different communicative functions in speech acts (Horezeanu, 2015). In most Arabic dialects, these religion-related forms can be used for social interactions to show chords, reject requests or express hope or confusion (Maalej, 2018), but generally used as mitigating devices to mitigate direct requests as well as response to requests in Arabic.

\section{Methodology and Data Analysis}

\subsection{Data collection and sample}

The paper will evaluate the four examples of request making of a Saudi family. The data for the analysis was collected from a Saudi TV show that was broadcasted on YouTube as well as on different Saudi channels in 2013. The online sources can be found in Table 1 .

Table 1: Record of sources of communication in Saudi family

\begin{tabular}{|c|c|c|c|}
\hline Communication & Orators & Source & Duration \\
\hline 1 & $\begin{array}{c}\text { Husband- } \\
\text { Wife } \\
\text { Mom-Son }\end{array}$ & $\begin{array}{c}\text { https://www.youtube.com/w } \\
\text { atch?v=BhFykm2zL0M } \\
\text { https://www.youtube.com/w } \\
\text { atch?v=OygHbF4WDRM }\end{array}$ & 21:43-21:55 \\
\hline 2 & $\begin{array}{c}\text { Sister- } \\
\text { Brother }\end{array}$ & $\begin{array}{c}\text { https://www.youtube.com/w } \\
\text { atch?v=iFT_ffmr }\end{array}$ & $17: 12-17: 29$ \\
\hline 3 & $\begin{array}{c}\text { Mom- } \\
\text { Daughter }\end{array}$ & $\begin{array}{c}\text { https://www.youtube.com/w } \\
\text { atch?v=-v8Fkyybi04 }\end{array}$ & $06: 02-6: 17$ \\
\hline 4 & & & \\
\hline
\end{tabular}

Table 1 presents the record of sources of data used to represent communication in a typical Saudi family. There are four communication examples used. One is between a husband and wife; another is between mom and son; third is between sister and brother; fourth is between mom and daughter. Main source of these communications is YouTube. Their length is fairly short which is representative to what the article attempts to shed light on. The referred to material is a television program that is broadcasted over 30 episodes every year. The data are taken from three different episodes of 2016 version. The program is called Shbab Albomb (Derek Baldwin, 2017), meaning 'new youth'. It is in Arabic and has no English subtitles. This program shows how the Saudi family communicates with each other in their homes, and highlights different aspects of their daily life. The events of the show take place in Riyadh, in the heart of Saudi Arabia. The Arabic dialect, spoken, is called Arabic Najdi. The extracts provide examples of direct requests and FTAs. The excerpts are translated using Jefferson (2004). Transcription Standard is represented in table 2 below. 
Table 2: Transcription standard following Jefferson (2004)

\begin{tabular}{|l|l|}
\hline Sign & Denotation \\
\hline I.. & Expressive pitch \\
\hline$\ldots ? .$. & Increasing tone \\
\hline @..@ & Physical act that is seen \\
\hline (..) & Define sounds \\
\hline
\end{tabular}

Table 2 shows the signs used in the transcription of the communication examples along with their denotations. The paper analyzes and discusses the four short personal conversations between family members. Four members of the family, a father, a son, a daughter and a mother participated in the conversation, using Najdi Arabic dialect.

\subsection{Data analysis}

This article adopts the analysis protocol proposed by Blum-Kulka (1984). The three main categories include "address terminology" for addressing, "header behavior request", and "support actions" (Blum-Kulka) for the reduction or mitigation of request (1984). In addition, open is left open to any accommodating categories I would add to analyse, for example, the use of Insha'Allah and MashaAllah once prompted (under the 'category of religious responses, for instance).

\subsubsection{Interaction (A)}

During the lunch period, the husband asks his wife to bring hot sauce (khalejiatv, 2016, June 21).

A. Husband: just? go get the hot sauce.

B. Wife: /Inshallah/ I will get it what else you want?

A. Husband: Nothing only hot sauce but? quickly?

B. Wife: Just wait and I will bring it Insha'Allah

Head act: To get hot sauce, direct request was made (line 1).

Address term: 'just' was used in order to end the conversation and to get prepared for request made.

Supportive move: It was not used.

Religious form: Inshallah (line 2) which in this context can be translated as 'okay'. Inshallah is confirming and agreeing with the request to bring the hot sauce.

In Saudi culture, husband and wife respect each other and participate directly in FTA. The main role of the family is to sign FTA. In this interaction, the wife asked her husband what else, and the Insha'Allah (line 2) said in a low voice, the voice did not go up. She smiled too during the conversation. However, the husband tried to minimize his request, using "only" (line 3) and using "quickly" to improve the sound. In this case, this is the wife's FTA. However, this is not the case, and Insha'Allah is a promise (that might be fulfilled).

\subsubsection{Interaction (B)}

The son (S) comes to his mother (M) asking her for money for a trip with his friends (khalejiatv, 2016, June 21).

A. S: hello dear mother! You are looking beautiful and younger to be my mother.

B. M: @ smiling@ sto?p

A. S: really mother I had to confess every day you become prettier and younger; how you do that?

B M: ok, I know your moves. @ rising her eyebrows@ do you want anything?

A. S: just $5000 \mathrm{R}$ [money] my friends and I will go to Dubai

B. M: /?mashallah/.

A. S: I promise I will return the amount you once I will go to work.

B. M: ok @ smiling@I will g?ive it you.

Address term: Son is giving compliments to her mother (line 1 and 3).

Head act: 5000 Riyals were requested (line 5).

Supportive move: minimizing the request just (line 5) and promises to give the money back (line 7).

Religious form: Shows surprise (line 6).

In Saudi culture, the mother is responsible for managing the financial status of the family. Son is expressing his admiration, praise of his mother (line 1), especially when he needs something, the son admires, which is considered polite. In lines 1 and 3, the son tried to impress his mother before making the request. However, the mother noticed and asked directly the reasons for this courteous attitude. The child used a minimization strategy to reduce his request face threat. The mother used the word "MashaAllah" in line 6, and her tone kept growing. This answer is face threatening act (FTA) of the child, because the mother can reject his request. 


\subsubsection{Interaction $(\mathbf{C})$}

The sister (S) asks her brother (B) to take her to her friend's house (khalejiatv, 2017, June 08).

A. S: (shouts her brother's name) A?mer

B. B: w?hat what?

A. S: I want you to take me to my friend house.

B. B: why inshallah?

A. S: my mother said that.

B. B: ok! but quietly.

Address term: calls her brother's name Amer (line 1).

Head act: The request is to take her to her friend's house (line 3).

Supportive move: I want you (line 3).

Religious form: It shows surprise (line 4).

This interaction shows that my sister asks her brother directly to get in line. However, the brother answered in line 4 and used Insha'Allah as a satirical strategy to improve his voice, a way to reject his request, which could lead to an agreement on the free exchange of the sister. The sister answered immediately at $5 \mathrm{am}$ and her mother gave her permission. In this case, this agreement is on the free exchange of the brother; while the mother agrees, his refusal does not matter. The relationships between brothers and sisters in Saudi Arabia are the same.

\subsubsection{Interaction (D)}

The daughter $(D)$ comes to her mother $(M)$ to inform her that she will go out with her friends (khalejiatv, 2017, June

02).

A. D: mo?m do you want something, @looking at her phone@?

B. M: where you going /inshallah/? (In high tone).

A. D: out with my friends.

B. M: n??o n?o no.

A. D: why in?shallah??

B. M: because you are co?ming after you already pl?aned, de?cided, wore your fancy clothes and put makeup.

You just came to inform, not to ask a permission!

Address term: mom (line 1).

Head act: The request is to go out with her friends (line 3).

Supportive move: not used.

Religious form: inshallah in line 2 shows upset, and in line 4 it shows anger.

In this interaction, the daughter told her mother that she would go with her friends. The request is not an FTA. In the first line, the daughter asks her mother directly. She does not ask permission to leave. This directness is considered a rude attitude, especially of the daughter. For women in Saudi culture, this is not an idea, even if you are a teenager; because you are still considered a child. The mother in the second line asked her daughter, with mother's voice was very sad. In addition, the mother has repeatedly declared "no"; this is an FTA of the daughter. Mom in the second and fourth line was very angry; she kept saying "no" and gave their daughter the opportunity to talk. The daughter feels uncomfortable in line 5, and says "why" (and uses the voice of) "Insha'Allah" to express disagreement and anger.

\section{Findings and Discussion}

The main finding of the data analysis is the basic consultation strategy used by members of the Saudi family when approaching a request. Blum-Kulka et al. (1989) also found that most members of the Saudi family use direct requests. Blum-Kulka et al. (1989) offers three levels of directness, and the above interaction apparently follows the righteousness of the first level. Among the four family interactions, there is a level of direct research strategy (Tawalbeh \& Al-Oqaily, 2012), which is also found in his study of the directness of Saudi Arabia. If the request is not serious Tawalbeh and Al-Oqaily (2012) believe that members of the United States have a group of friends and family members. This is similar to the use of direct discourse by members of the Saudi family, but the Saudi family asks directly, even if it makes a great demand. The interaction of Arabs, particularly Saudi Arabia, seems more direct than the proposed proposal in Italian. Moreover, Economidou-Kogetsidis (2005) indicated that the direct consultations concern clarity, form, and purpose, which are considered to be learned both in the United Kingdom and in Greece. It can be said that this direct request is also polite in the question of Saudi Arabia. The Blum-Kulka (1984) also indicated that FTA could originate in the request, but in the Saudi Arabian family request the FTA corresponds to the power of hearer(s) which might be in line with Brown and Levinson's (1987) argument about that a direct response is due to the ability to respond to the public (and an individual).

112 
When it comes to Bloom-Kulka (1984) argument about that the FTA can be reduced by minimizing consultations, in the interaction of the Saudi family, the father and the son were seen to minimise their requests to the mother/wife, but in this case, they will not lose status, because the mother has the right to make decisions at home.

Family members have different ways to mitigate their direct requests, which can also be influenced by sex and family member-status. The boy used various auxiliary actions to make a direct request to the mother. However, her daughter does not rely on Saudi culture. The son seems to be closer to the mother than to the daughter, because he uses several compliments to try to make the mother happy. For a Saudi family, it is not right for the daughter to use such strategy. The mother must be respected, because she is the family head in the quoted situations. She is responsible for finances. I know that the children's direct needs should be met, but direct requests can be considered rude (as in the case of the daughter).

The Arabic language is influenced by Islamic teaching-forms and culture, and that can be traced when the language is used. The mothers responded to requests, using Insha'Allah and MashaAllah. It does this before the FTA. Among other cultures, such as the Tzeltal, Tamil, and English culture, FTA is mainly made in the request (Brunn \& Levinson, 1987). In the Saudi case, the direct confrontation takes place without threats to accepting the requests; and the answer to requests sound threatening the requesting person, especially when using religious terminologies that are themselves used in as mitigating tool. MashaAllah and Insha'Allah are used in the language in order to refer various emotional reactions, such as surprise, irony, anger, and anxiety. These interjections are mainly used in Saudi conversations to show the response of the receiver of the request/ target of request.

Interestingly, non-native Arabic users may find it difficult to realize such religious forms' meaning. The use of MashaAllah has different interpretations and functions, especially alongside raised voice or in a special way of uttering the form. That said, data analysis shows strong verbal support to that Najdi's local Arab users use in their interactions religious terms such as MashaAllah and Insha'Allah, especially when they respond to requests. However, in other parts of Saudi Arabia, this could be not the case (Albalavi, 2015). These forms of religious terms have different meanings, depending on the way of their pronunciation and accompanied tone and intonation.

\section{Conclusion}

This paper has analyzed recorded data on interactions between family members in Saudi Arabia. The interactions were typical of the classic Saudi Arabian (as well as other Arab) family life. Results demonstrate the impact of the cultural and gender on Saudi familial interaction, namely making and responding to requests and their directness. Interactants' responses often included Islamic methods to reduce FTA, and to express feelings of unhappiness or surprise. The use of MashaAllah and Insha'Allah was typical in interaction, and obvious in the context of parents' interactions.

The use of intonation in the expression of Islamic forms is considered a way of responding to direct questions and requests. Furthermore, the role of the mother in the family was seen an important, and a driver for the use of the religious forms which proved having multiple functions with the different family members making requests, taking into account that the mother plays several roles in the house, including managing finances and preparing food. These several roles may require using the same forms but to function differently in proportionate with the type relationship between the mother and every other member of the family, including the husband. This seems to be in affinity with what Brown and Levinson (1987) have suggested in regards to the occasional need for an FTA.

In a nutshell, familial relationship, sex of interactants, role of interactants, age and culture seem to be the determinants of directness for Saudi family members when approaching requests. Culture, particularly the Islamic culture was found to be influencing the choice of request-response strategies as it was evident in using 'Masha Allah' and 'Insha Allah'. Finally, the everyday interaction between Saudi family members does raise perceived face threat issue due to 'directness' as in daughter-mum interaction and husband-wife interaction.

\section{References}

Al-Kahtani, S. (2005). Refusals realizations in three different cultures: A speech act theoretically-based cross-cultural study. Journal of King Saud University, 18, 35-57.

Al-Marrani, Y. and Sazalie, A. (2010). Polite Request strategies by Yemeni Females: A socio-pragmatic study. Modern Journal of Applied Linguistics, 2(6), 478-516.

Albalawi, H. (2015). Changes in the Balawiy Bedouin Arabic dialect of Saudi Arabia 1985-2015. (Doctoral dissertation).

Austin, J. (1975). How to do things with words: Oxford university press. 
Blum-Kulka, S. (1984). Requests and Apologies: A cross-cultural study of speech act realization patterns (CCSARP). London: Oxford University Press.

Blum-Kulka, S. (1987). Indirectness and politeness in requests: Same or different? Journal of Pragmatics, 11(2), 131146.

Blum-Kulka, S., House, J., and Kasper, G. (1989). Cross-cultural pragmatics: Requests and apologies (Vol. 31). New York, NY: Ablex Pub.

Blum-Kulka, S., and Olshtain, E. (1984). Requests and apologies: A cross-cultural study of speech act realization patterns (CCSARP). Applied Linguistics, 5(3), 196-213.

Bowe, H. (2014). Schemas, facAe and politeness / Heather Bowe. In K. Martin \& H. Manns (Eds.), (2nd ed.. ed.). Cambridge: Cambridge: Cambridge University Press.

Brown, P., and Levinson, S. (1987). Politeness: Some universals in language usage (Vol. 4). Cambridge: Cambridge University Press.

Commins, D. (2015). Islam in Saudi Arabia: IB Tauris.

Cultural Portfolio (2006). Saudi Arabia: Family. Retrieved from http://dpuadweb.depauw.edu/\$1 mkfinney/teaching/Com227/culturalPortfolios/Saudi_Arabia/Family.htm

Derek Baldwin, C. (2017). Comedies, TV series top Ramadan viewing list. Retrieved from https://gulfnews.com/news/uae/media/comedies-tv-series-top-ramadan-viewing-list-1.2038235

Economidou-Kogetsidis, M. (2005). "Yes, tell me please, what time is the midday flight from Athens arriving?': Telephone service encounters and politeness. Intercultural Pragmatics, 2(3), 253-273.

Horezeanu, M. (2015). You Want to Hear the Magic Word? Inshallah. British and American Studies, 21, 193.

Huang, Y. (2006). Pragmatics: Oxford University Press.

Jefferson, G. (2004). Glossary of transcript symbols with an introduction. Pragmatics and Beyond New Series, 125, 1334.

khalejiatv. (2016, June 21). Shbab Albomb. Retrieved from https://www.youtube.com/watch?v=OygHbF4WDRM

khalejiatv. (2017, June 02). Shbab Albomb. Retrieved from https://www.youtube.com/watch?v=-v8Fkyybi04

khalejiatv. (2017, June 08). Shbab Albomb. Retrieved from https://www.youtube.com/watch?v=iFT_ffmr16A

Krulatz, A. (2012). Interlanguage pragmatics in Russian: The speech act of request in email. Salt Lake, US: The University of Utah.

Maalej, Z. (2018). Inshallah in compliance to requests and invitations: A social cognition perspective. Saudi Arabia.

Ogiermann, E. (2008). On the culture-specificity of linguistic gender differences: The case of English and Russian apologies.(Report). Intercultural Pragmatics, 5(3), 259. doi:10.1515/IPRG.2008.013

Searle, J. (1975). Indirect speech acts. In Cole, P. \& J Morgan (Eds.), Language in Society, 59-82.

Tawalbeh, A., and Al-Oqaily, E. (2012). In-directness and politeness in American English and Saudi Arabic requests: A cross-cultural comparison. Asian Social Science, 8(10), 85-98.

Wallentin, M., and Frith, C. (2008). Language is shaped for social interactions, as well as by the brain. Behavioral and brain sciences, 31(5), 536-537. doi:10.1017/S0140525X0800527X 